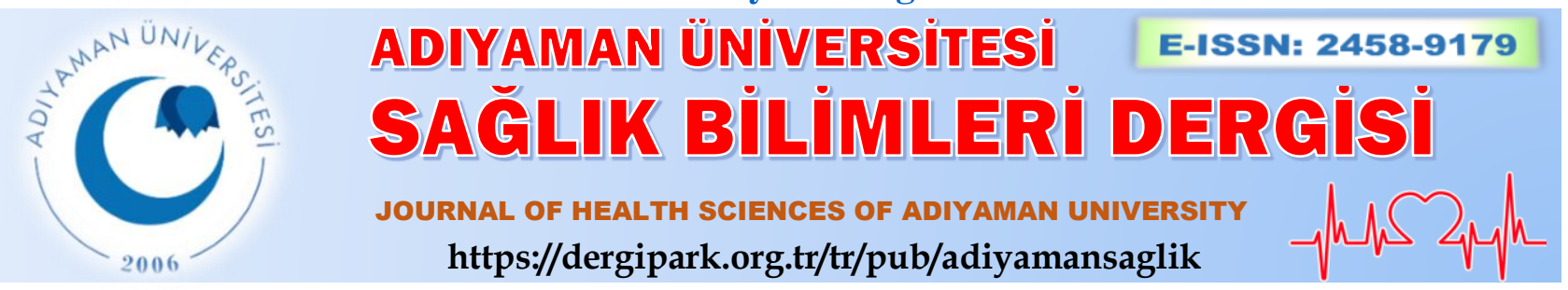

Özgün Araştırma/Research Article

\title{
Korakoid morfolojisi ve korakohumeral mesafenin değerlendirilmesi
}

\section{The evaluation of the coracoid morphology and the coracohumeral distance}

\author{
Abdulkadir SARI @(D), Hadi SASANi ${ }^{2}$ (D) Yaşar Mahsut DINÇEL ${ }^{1}$ (D) Mehmet Ümit ÇETIN $^{1}$ (D) \\ İlker YILDIRIM ${ }^{3}$ (D) Ayhan ŞAHIN ${ }^{3}\left(\mathbb{D}\right.$, İsmail AĞIR ${ }^{4}(\mathbb{D}$ \\ ${ }^{1}$ Namık Kemal Üniversitesi, Tıp Fakültesi, Ortopedi ve Travmatoloji Anabilim Dalı, 59100, Tekirdağ-Türkiye \\ ${ }^{2}$ Namık Kemal Üniversitesi Tıp Fakültesi, Radyoloji Anabilim Dalı, 59100, Tekirdağ-Türkiye \\ ${ }^{3}$ Namık Kemal Üniversitesi, Tıp Fakültesi, Anestezi ve Reanimasyon Anabilim Dalı, 59100, Tekirdağ-Türkiye \\ ${ }^{4}$ Adıyaman Üniversitesi Tıp Fakültesi, Ortopedi ve Travmatoloji Anabilim Dalı, 02040, Adıyaman-Türkiye
}

Atıf gösterme/Cite this article as: Sarı A, Sasani H, Dinçel YM, Çetin MÜ, Yıldırım İ, Şahin A, Ağır İ. Korakoid morfolojisi ve korakohumeral mesafenin değerlendirilmesi. ADYÜ Să̆llk Bilimleri Derg. 2020;6(2):182-189. doi:10.30569.adiyamansaglik. 712700

$\ddot{O} \mathbf{z}$

Amaç: Çalışmamızdaki amacımız, omuz sıkışmasında etkili olduğunu düşündüğümüz korakoid morfolojisini ve korakohumeral mesafeyi ortaya koymaktır.

Gereç ve Yöntem: Her iki omuzda korakoglenoidal aralık tipi, korakoid açılanması ve korakohumeral mesafeler ölçüldü. Olguların yaş, cinsiyet, taraf, boy uzunluğu ve el dominansı ile elde edilen sonuçlar arasındaki korelasyonlar değerlendirildi.

Bulgular: Her iki omuz korakohumeral mesafe değerleri erkeklerde kadınlardan daha yüksek bulundu $(p<0,05)$. Yaş ile korakoid açılanma ve korakohumeral mesafe değerleri arasında negatif korelasyon tespit edildi $(p<0,05)$. Olguların boy uzunluklarıyla korakohumeral mesafe değerleri arasında pozitif korelasyon görüldü $(p<0,05)$. Her iki cinsiyette açılanma değerleriyle korakohumeral mesafe değerleri arasında herhangi bir korelasyon tespit edilmedi.

Sonuç: Çalışmamız, korakoid açılanması ve korakohumeral mesafe değerlerini ortaya koymanın yanısıra, el dominansı ve korakoid açılanmanın korakohumeral mesafe üzerinde etkisi olmadığını göstermiştir.

Anahtar Kelimeler: Korakoid; Korakohumeral mesafe; Subkorakoidal sıkışma; Subskapularis kası.

\begin{abstract}
Aim: To reveal the coracoid morphology and coracohumeral distance, which is believed to have an impact on shoulder impingement.

Materials and Methods: The type of the coracoglenoidal space, coracoid angulation and coracohumeral distances were assessed for both shoulders. Correlations between age, gender, side, height and hand dominance of the cases were investigated.

Results: The coracohumeral distance values were significantly higher in both shoulders in males $(p<0,05)$. A negative correlation was found between age and the coracoid angulation and coracohumeral distance values $(p<0,05)$. A positive correlation was detected between the height and the coracohumeral distance of the cases $(p<0,05)$. There was no correlation between the angulation values and the coracohumeral distance values in both genders.

Conclusion: The current study has revealed the values of coracoid angulation and coracohumeral distance values. It has also demonstrated that hand dominance and coracoid angulation did not have an impact on the coracohumeral distance.

Keywords: Coracoid; Coracohumeral distance; Subcoracoid impingement; Subscapularis muscle.
\end{abstract}

Yazışma Adresi/Address for Correspondence: Abdulkadir SARI, Namık Kemal Üniversitesi Tıp Fakültesi, Ortopedi ve Travmatoloji Kliniği, Süleymanpaşa, 59100, Tekirdağ-Türkiye, E-mail: drortopedist@yahoo.com

Geliş Tarihi/Received:01.04.2020 Kabul Tarihi/Accepted:14.05.2020 Yayım Tarihi/Published online:30.08.2020 


\section{Giriş}

Omuz sıkışma sendromu omuzdaki en yaygın ağrı kaynağıdır. ${ }^{1,2}$ Tanımlandığı günden itibaren omuzdaki sıkışmanın subakromiyal bölgede geliştiği nadiren subkorakoidal bölgeden kaynaklandığ 1 düşünülmüştür. ${ }^{3}$ Ancak, güncel çalışmalar, supraspinatus yırtı̆gıyla subskapularis yırtığının birlikteliğini göstermekte ve rotator kaslar üzerinde sadece akromiyonun değil korakoid morfolojisininde etkili olduğunu bildirmektedir. $^{4,5}$ Omuz anteriorundaki sıkışma günümüzde hala tam olarak anlaş1lamamıştır. ${ }^{6}$

Subkorakoid sıkışma omuzun fleksiyon, addüksiyon ve internal rotasyon hareketi esnasında subskapularis (SS) kasının korakoidle humerus başı arasındaki sıkışmasıdır., ${ }^{6,7}$ Korakohumeral mesafedeki (KHM) daralma ile SS kas patolojileri arasında ilişki güncel literatürde bildirilmektedir. ${ }^{8}$ Giaroli ve ark., ${ }^{9}$ kadınlarda korakoid-küçük tüberkül arası mesafenin daha dar olduğunu bununda sıkışma sendromuyla yakın ilişkisini belirtmiştir. Dugarte ve ark. ${ }^{10}$ ise, yaşla birlikte subkorakoidal mesafenin daraldığını ve her iki cinsiyetin yaşlı olgularında korakoidin hook şeklinde olduğunu bildirmiştir.

Çalışmamızdaki amacımız, omuz sıkışmasında etkili olduğunu düşündüğümüz korakoid morfolojisini ve korakohumeral mesafeyi ortaya koymaktır.

\section{Gereç ve Yöntem}

Çalışma için, ilgili üniversite Tıp Fakültesi Etik Kurulu'ndan etik kurul izni alınmıştır. (24.09.2019-2019.171.09.31). Araştırma Helsinki Bildirgesi ilkelerine uygun olarak yürütülmüştür. Hastane PACS sistemi kullanılarak olguların her iki omuzları toraks bilgisayarlı tomografi (BT) görüntüleri üzerinden retrospektif olarak değerlendirildi. Olgulara telefonla ulaşılarak çalışmaya dâhil edilme kriterleri sorguland. 18-60 yaş aralığında, daha önce dejeneratif, travmatik yada konjenital omuz problemi olmayan ve omuz cerrahisi geçirmemiş olgular çalışmaya alındı. Yirmi olgu çalışma dışı bırakılarak, toplam 100 olgu çalışmaya dahil edildi.
Ölçümler ve tiplendirme, her iki omuzu içeren BT kesitlerinde aksiyel ve üç boyutlu görüntüler kullanılarak bir ortopedist ve radyolog tarafindan gerçekleştirilmiştir. Toraks BT taramaları ToshibaAquilion ${ }^{\mathrm{TM}}$ PRIME 80 (Toshiba Medical Systems Corp., Tokyo, Japonya) cihazında yapıldı. Kullanılan toraks BT parametreleri $\mathrm{kV}: 120$, mAs: 80 , kolimasyon: $1.25 \times 1.25 \mathrm{~mm}$, aralık: 1 , FOV: $20 \times 20 \mathrm{~cm}$, matris: $512 \times 512$ ve dilim kalınlığı: $1 \mathrm{~mm}$ şeklinde idi. Ham veriler deneyimli bir radyolog tarafindan Sectra PACS sistemi (Sectra AB, Linköping, İsveç) üzerinde işlendi ve çok düzlemli rekonstrüksiyon (multiplanar reconstruction, MPR) görüntüleri elde edildi.

Korakoid açılanması aksiyel sekanslar üzerinde, korakoidin bazisi ile uç kısmı arasındaki açılanma derecesi olarak ölçüldü (Şekil 1). KHM ise yine aksiyel sekanslar üzerinde milimetre $(\mathrm{mm})$ cinsinden korakoid tipinin arka kısmıyla humerus arasındaki en kısa mesafe olarak kabul edildi (Şekil 2). Korakoglenoidal aralık Gumina ve ark.'nın ${ }^{11}$ tanımladığı şekilde, oluşturulan üç boyutlu görseller üzerinden korakoid arkası ile glenoid ön-üst kısmı arasındaki aralığın şekline göre yapıldı. Buna göre Tip 1 yuvarlak, Tip 2 kare, Tip 3 ise balık kancası şeklinde tanımlandı (Şekil 3). Olguların taraf, yaş, cinsiyet, boy uzunluğu ve el dominansı karşılaştırmalarda kullanmak için kaydedildi.

İstatistiksel analizler SPSS v.17.0 programı yardımıyla gerçekleştirilmiştir. Değişkenlerin normal dağılıma uygunluğu histogram grafikleri ve Kolmogorov-Smirnov testi ile incelendi. Tanımlayıcı analizler sunulurken ortalama, standart sapma, ortanca değerler kullanıldı. Karşılaştırmalar $2 \times 2$ gözlerde Pearson ki-kare ve Fisher kesin ki-kare testleri ile yapıldı. Normal dağılım gösteren (parametrik) değişkenler gruplar arasında değerlendirilirken bağımsız gruplar için $\mathrm{t}$ testi, normal dağılım göstermeyenler (nonparametrik) gruplar arasinda değerlendirilirken Mann-Whitney $U$ testi kullanılmıştır. Ölçümsel verilerin birbirleri ile analizinde Spearman korelasyon testinden faydalanılmıştır. $p$ değerinin 0,05 'in altında olduğu durumlar istatistiksel olarak anlamlı sonuçlar şeklinde değerlendirildi. 


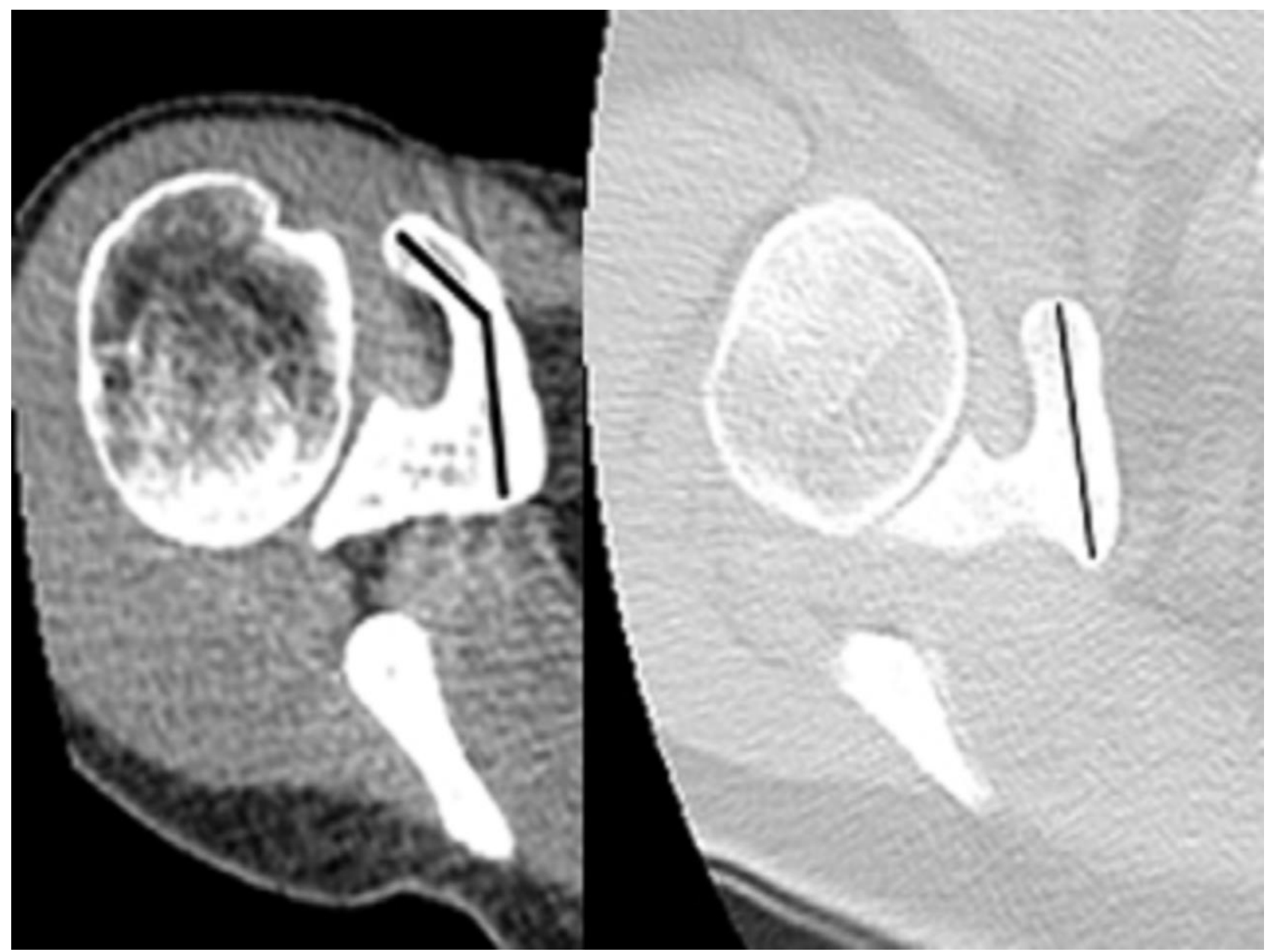

Şekil 1. Korakoid açılanmanın ölçülmesi.

\section{Bulgular}

Çalışmaya 50 erkek ve 50 kadın olmak üzere 100 hasta dâhil edildi. Hastaların yaş ortalamas1 $40,74 \pm 11,52$ y1l, boy ortalamas1 $169,72 \pm 7,96 \mathrm{~cm}$ idi. Olguların 79'unda sağ, 21 'inde sol el dominanttı. Korakoid açılanma sonuçlarımız iki cinsiyet arasında anlamlı bir fark göstermezken, KHM değerleri erkeklerde her iki omuzda daha yüksek bulundu $(p<0,05)$ (Tablo 1).

Korakoid açılanma ve KHM değerlerinin sağ ve sol omuzlar arasında benzerlik gösterdiği görülürken ( $p>0,05)$ (Tablo 2$)$, el dominansının korakoid açılanması ve KHM üzerinde etkisi olmadığı bulundu $(p>0,05)$ (Tablo 3). Olguların yaşı ile korakoid açılanma ve KHM değerleri arasında negatif, boy uzunluklarıyla KHM değerleri arasında pozitif korelasyon saptand $1(p<0,05)$ (Tablo 4). Her iki cinsiyette de açılanma değerleriyle KHM değerleri arasında herhangi bir korelasyon tespit edilmedi (Tablo 5).
Korakoglenoidal aralık tiplendirildiğinde, en sik Tip 1 (sağ:\%62, sol:\%64), ikinci sıklıkta Tip 3 (sağ:\%25, sol:\%24) izlenirken, Tip 2'nin(sağ:\%13, sol:\%12) en düşük sıklıkta görüldüğü bulundu. Sağ ve sol omuzlarda korakoid tipleri arasinda benzerlik vardı $(p>0,05)$. Cinsiyetler açısından değerlendirildiğinde, olguların benzer korakoglenoidal tiplere sahip olduğu görüldü $(p>0,05)$. El dominansinin tiplendirme üzerinde etkili olmadığı gözlendi $(p>0,05)$.

Ölçümler arasında güvenilirlik korelasyon katsayısı korakoid açılanması için 0,769 [\%95 G.A. 0,507-0,891], KHM için 0,784 [\%95 G.A. 0,605-0,904] bulundu.

\section{Tartışma}

Subkorakoidal sıkışma, bu bölgedeki yapıların volüm artışı ya da aralığın daralmasına bağlı olarak gelişebilir. Subskapularis kasinda kalsifikasyon yada kemikleşme, bursit ve gangliyon gibi durumlar ilkine örnek iken, korakoid varyasyonları, tüberkulum minus anomalileri 
ve humerus başının translasyonu ikinci mekanizmaya örnektir. ${ }^{7,12,13}$ Her iki mekanizma sonrası bu bölgedeki SS kası, glenohumeral ligament ve biseps tendonunun uzun başı humerus başıyla korakoid arasında sıkışır. ${ }^{14}$ Yapılan çalışmalar KHM'nin normal değerini 8,7 ila $11 \mathrm{~mm}$ olarak belirtmektedir. ${ }^{13,15}$ Leite ve ark., ${ }^{16}$ yaptıkları çalışmada ortalama KHM değerini $8,6 \pm 3,0$ mm bulmuşlar ve cinsiyetler arasında farklılık gözlememişlerdir. Bununla birlikte, sağlıklı kontrol grubunda KHM değerini 10,3 $\pm 2,2$ mm bulurken, SS kası komplet yırtığında $5,0 \pm 1,7 \mathrm{~mm}$ bulmuşlardır. Benzer şekilde biseps uzun başında lezyon olmayan kontrol grubunda KHM değeri 9,2 $\pm 2,9 \mathrm{~mm}$ bulunurken, lezyonlu grupta $7,1 \pm 2,7 \mathrm{~mm}$ bulunmuştur. Kendi çalışmamızda elde ettiğimiz KHM değerleri literatürle uyumluydu. Erkeklerde (sağ: 10,20 $\pm 2,16 \mathrm{~mm}$, sol: $10,16 \pm 2,28 \mathrm{~mm}$ ), kadınlarda (sağ: 9,22 $\pm 1,71 \mathrm{~mm}$, sol: 9,22 $\pm 1,62 \mathrm{~mm}$ ).

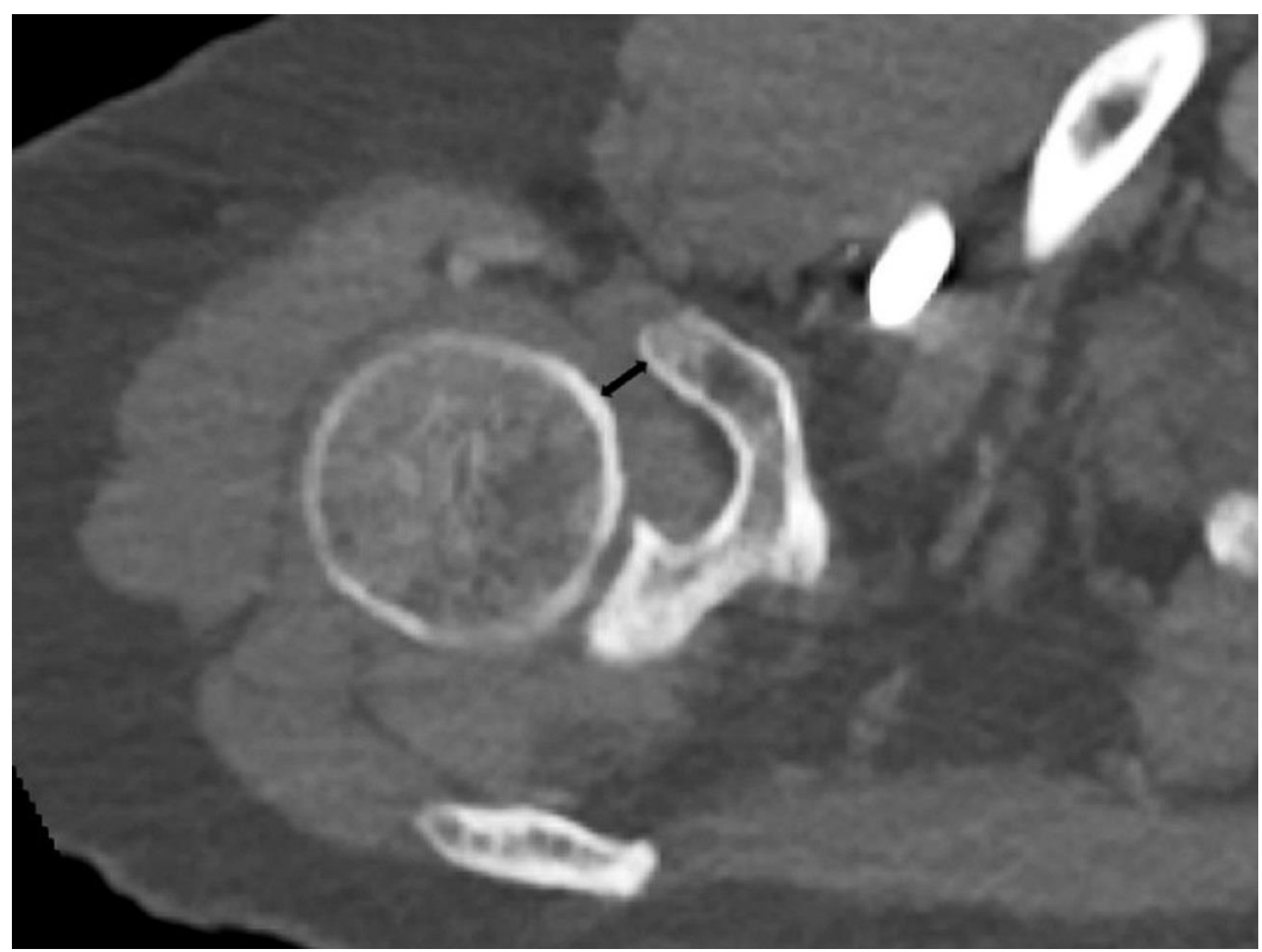

Şekil 2. Korakohumeral mesafenin ölçülmesi.

Korakoid morfolojisiyle ilgili ilk çalışmalar korakoglenoidal boşluğun şekli üzerineydi. ${ }^{11,17}$ Gumina ve ark.'nın ${ }^{11}$ kadavra çalışmasında, korakoglenoidal aralık tiplendirildiğinde en s1k \%45 ile Tip 1, en az ise $\% 21$ ile Tip 3 gözlenmiştir. Yazarlar, en kısa korakoglenoidal uzunluğun Tip 1 olgularda olduğunu ve bu olguların subkorakoidal sıkışma için riskli grup olduğunu belirtmişlerdir. Verma ve ark. ${ }^{17}$ güncel kuru kadavra çalışmalarında, benzer şekilde, olguların \%44'ünde Tip 1, \%18'inde ise Tip 3 korakoid izlediklerini aktarmışlardır.
Bizde kendi popülasyonumuzda literatürle uyumlu şekilde en s1k Tip 1 korakoid morfolojisini tespit ettik.

Günümüzde artan sayıda olguda ön omuz sıkışması tanısı konmaktadır. ${ }^{18,19}$ Ek olarak subkorakoidal sıkışmanın subakromiyal sıkışma ve rotator kas patolojileriyle birlikteliğine sıkça rastlanmaktadır. ${ }^{20,21}$ Lo ve ark., ${ }^{6}$ rotator kas yırtıklı olguların \%19'unda hem akromiyon hemde korakoid çevresinde sıkışma olduğunu göstermişlerdir. Subkorakoidal sıkışmanın özellikle rotator kas onarımı sonrası rezidü ağrının kaynağı 
olabileceğide belirtilmektedir. ${ }^{16,20}$ Açılanmış ya da elonge korakoidin sıkışmaya neden olduğu yine literatürde bildirilmektedir. ${ }^{22}$ Dugarte ve ark. ${ }^{10}$ kuru kadavra üzerinde yaptıkları çalışmada korakoid kemiği morfolojik olarak düz, kanca veosteofitik diye üçe ayırmışlar, yaşlı örneklerin \%49'unda kanca şekilli korakoidi saptarken, genç olgularda bu oranı daha düşük (\%29) bulmuşlardır $(p<0,0001)$. Yazarlar, erkek ve kadın örnekler arasında hem subkorakoid mesafeleri hemde korakoid morfolojinin benzer olduğunu ifade etmişlerdir. Asal ve Şahan' $1 n^{23}$ manyetik rezonans (MR) üzerinde korakoid tiplendirme yaptıkları çalışmalarında, SS patolojisi olmayan olgularda kanca şekilli korakoid morfolojisi olguların \%29,9'un görülürken, tendinozisli olguların $\% 65,2$, yırtıklı olguların ise $\% 48$ 'inde bu bulguya rastlamışlardır. En düşük $\mathrm{KMH}$ değerleri kanca tipinde görülmüştür $\quad(p=0,016)$. Çalışmamızda korakoid açılanma değerleri erkek ve kadınlarda farklılık göstermemekteydi. Erkeklerde (săg:147,92 $\pm 9,48$ derece, sol:

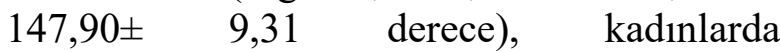

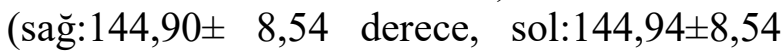
derece). Hem Giaroli ve ark. ${ }^{9}$ hem de Hekimoğlu ve ark. ${ }^{14}$ kadınlarda subakromiyal aralığın daha dar olduğunu belirtmişlerdir. Bizim KHM değerlerimizde bu sonuçlarla uyumlu olarak kadınlarda daha dar idi. Yaşlı olgularda literatürle uyumlu olarak saptadığımız daha dar açılı ve humerusa yakın korakoid morfolojisinin yaşlanma sürecinin bir sonucu olabileceğini düşünüyoruz. Kadın ve yaşlı olgularda elde ettiğimiz KHM'nin darlığ 1 bu olgularda daha sik görüldüğü belirtilen dejeneratif kas problemleri ve sıkışma bulgularıylada uyumludur. ${ }^{24}$

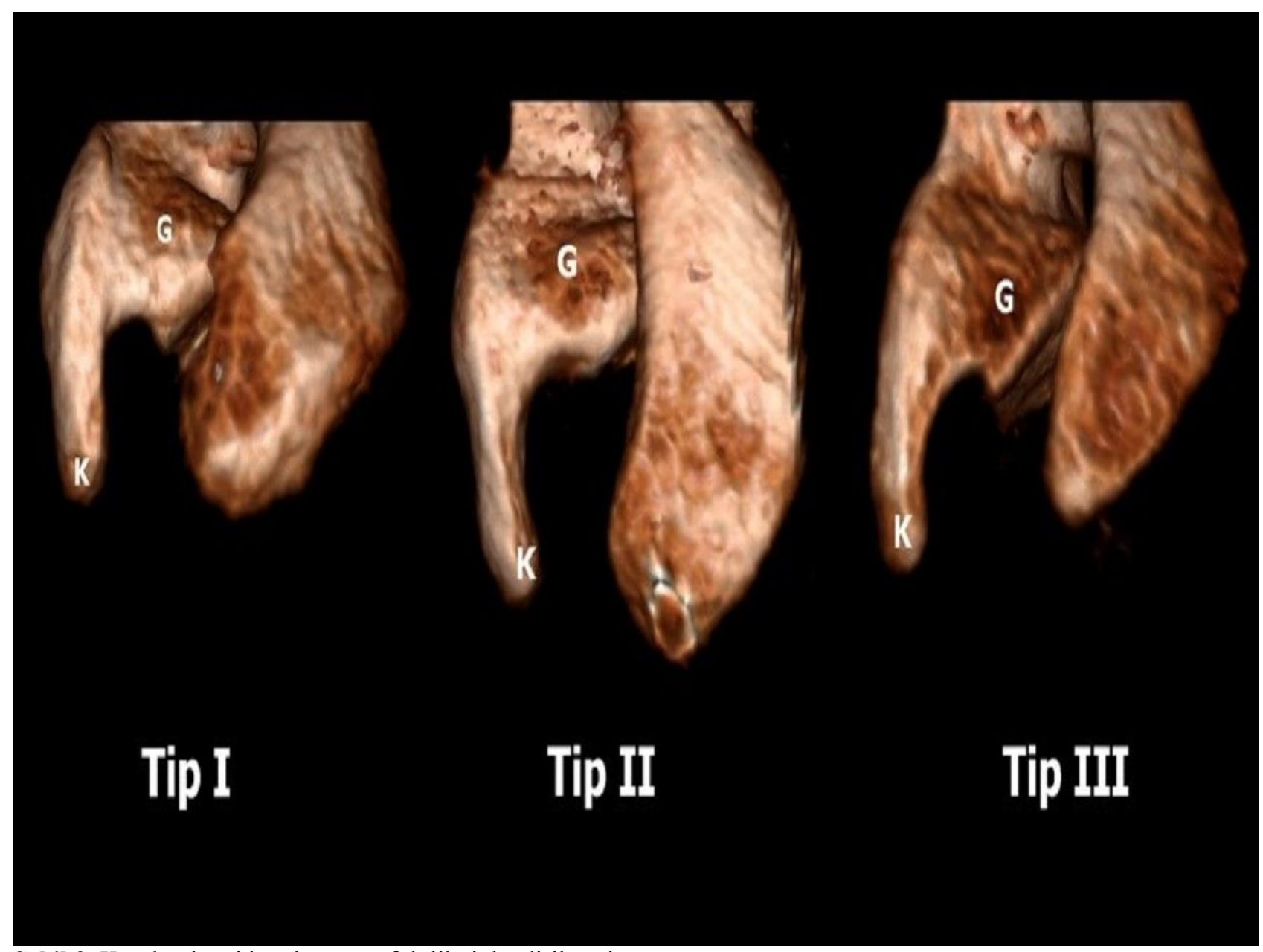

Şekil 3. Korakoglenoid aralığın morfolojik tiplendirilmesi.

Çalışmamız sonucunda KHM ile korakoid açılanması arasında bir ilişki tespit etmedik. $\mathrm{Bu}$ durum, açılanmanın tek başına korakoidle humerus başı arasındaki mesafe üzerinde etkili olmadığını düşündürtmektedir. Burada dinamik değişken olarak humerus başının önemli bir etkisi olduğunu düşünüyoruz. MacMahon ve ark.'nın ${ }^{25}$ belirttiği gibi, 
supraspinatus kas yırtığı sonrası değișen

korakoide yaklaşmasına neden olabilir.

glenohumeral dinamikler humerus başının

$\underline{\text { Tablo 1. Olguların tanımlayıcı istatistik verileri, her iki cinsiyette korakoid açılanma ve KHM değerleri. }}$

\begin{tabular}{|c|c|c|c|c|c|c|c|c|c|c|c|}
\hline & \multicolumn{3}{|c|}{$\begin{array}{r}\text { Erkek } \\
\end{array}$} & \multicolumn{3}{|c|}{ Kadın } & \multicolumn{3}{|c|}{$\begin{array}{r}\text { Total } \\
\end{array}$} & \multirow[b]{2}{*}{$p$} \\
\hline & & Ortalama & SS & Medyan & Ortalama & SS & Medyan & Ortalama & SS & Medyan & \\
\hline Yaş & & 40,36 & $\pm 11,45$ & 41,50 & 41,12 & $\pm 11,69$ & 43,00 & 40,74 & $\pm 11,52$ & 42,00 & $0,743^{\dagger}$ \\
\hline Boy & & 175,20 & $\pm 5,86$ & 176,00 & 164,24 & $\pm 5,68$ & 164,00 & 169,72 & $\pm 7,96$ & 168,50 & $<0,001 *$ \\
\hline Açılanma-săg & & 147,92 & $\pm 9,48$ & 148,50 & 144,90 & $\pm 8,54$ & 145,00 & 146,41 & $\pm 9,10$ & 146,00 & $0,097^{\dagger}$ \\
\hline Açılanma-sol & & 147,90 & $\pm 9,31$ & 149,50 & 144,94 & $\pm 8,54$ & 145,00 & 146,42 & $\pm 9,01$ & 147,00 & $0,101^{\dagger}$ \\
\hline KHM-sağ & & 10,20 & $\pm 2,16$ & 10,00 & 9,22 & $\pm 1,71$ & 9,00 & 9,71 & $\pm 2,00$ & 10,00 & $0,007^{*}$ \\
\hline KHM-sol & & 10,16 & $\pm 2,28$ & 10,50 & 9,22 & $\pm 1,62$ & 9,00 & 9,69 & $\pm 2,02$ & 10,00 & $0,005^{*}$ \\
\hline \multirow{2}{*}{ El dominansı } & Sağ & 41 & & $(82,00)$ & 38 & & $(76,00)$ & 79 & & $(79,00)$ & \multirow{2}{*}{$0,461^{\ddagger}$} \\
\hline & Sol & 9 & & $(18,00)$ & 12 & & $(24,00)$ & 21 & & $(21,00)$ & \\
\hline
\end{tabular}

KHM: korakohumeral mesafe, SS: standart sapma. ${ }^{*}$ Mann-Whitney U testi, ${ }^{\prime}$ bağgmsızgruplar için t testi, ${ }^{\ddagger} k i$-karetesti (ortalama \pm standart sapma yerine sayl, medyan yerine yüzde verilmiştir). Anlamlı $p$ değerleri kalın yazılmıştır.

Tablo 2. Sağ ve sol omuzlarda korakoid açılanma ve KHM değerleri.

\begin{tabular}{lccccccc}
\hline & \multicolumn{9}{c}{ Să } & Sol & \multicolumn{2}{c}{$\boldsymbol{p}$} \\
\cline { 2 - 7 } & Ortalama & SS & Medyan & Ortalama & SS & Medyan & $0,994^{\dagger}$ \\
\hline Açlanma & 146,41 & $\pm 9,10$ & 146,00 & 146,42 & $\pm 9,01$ & 147,00 & $0,951^{*}$ \\
KHM & 9,71 & $\pm 2,00$ & 10,00 & 9,69 & $\pm 2,02$ & 10,00 & 0 \\
\hline
\end{tabular}

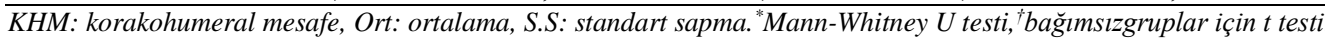

Tablo 3. El dominansı ile korakoid açılanma ve KHM değerleri arasındaki korelasyon.

\begin{tabular}{lccccccc}
\hline & \multicolumn{9}{c}{ El dominansı } & \multicolumn{1}{c}{ Sol } & $\boldsymbol{p}$ \\
\cline { 2 - 6 } & Ortalama & SS & Medyan & Ortalama & SS & Medyan & \\
\hline Açılanma-să & 146,24 & $\pm 9,77$ & 146,00 & 147,05 & $\pm 6,11$ & 147,00 & $0,643^{\dagger}$ \\
Açılanma-sol & 146,25 & $\pm 9,70$ & 147,00 & 147,05 & $\pm 5,87$ & 148,00 & $0,639^{\dagger}$ \\
KHM-să & 9,73 & $\pm 2,04$ & 10,00 & 9,62 & $\pm 1,86$ & 9,00 & $0,678^{*}$ \\
KHM-sol & 9,70 & $\pm 2,08$ & 10,00 & 9,67 & $\pm 1,83$ & 10,00 & $0,767^{*}$ \\
\hline
\end{tabular}

KHM: korakohumeral mesafe, SS: standart sapma. ${ }^{*}$ Mann-Whitney U testi, ${ }^{\dagger}$ bağımsızgruplar için t testi.

Tablo 4. Yaş ve boy uzunluk değerlerinin açılanma ve KHM değerleriyle korelasyonu.

\begin{tabular}{llcccccccc}
\hline & & \multicolumn{2}{c}{ Açılanma-să } & \multicolumn{2}{c}{ Açılanma-sol } & \multicolumn{2}{c}{ KHM-să̆ } & \multicolumn{2}{c}{ KHM-sol } \\
\cline { 3 - 8 } & & $\mathbf{r}$ & $\boldsymbol{p}$ & $\mathbf{r}$ & $\boldsymbol{p}$ & $\mathbf{r}$ & $\boldsymbol{p}$ & $\mathbf{r}$ & $\boldsymbol{p}$ \\
\hline \multirow{2}{*}{ Total } & Yaş & $-0,205^{*}$ & $\mathbf{0 , 0 4 1}$ & $-0,221^{*}$ & $\mathbf{0 , 0 2 7}$ & $-0,380^{* *}$ & $\mathbf{0 , 0 0 0}$ & $-0,368^{* *}$ & $\mathbf{0 , 0 0 0}$ \\
& Boy & 0,188 & 0,061 & 0,178 & 0,076 & $0,329^{* *}$ & $\mathbf{0 , 0 0 1}$ & $0,302^{* *}$ & $\mathbf{0 , 0 0 2}$ \\
\hline
\end{tabular}

KHM: korakohumeral mesafe. Spearman korelasyon testi. Anlamlı $p$ değerleri kalın yazllmıştır. $* p<0,05 * * p<0,01$

Tablo 5. Korakoid açılanma ve KHM değerleri arasındaki korelasyon.

\begin{tabular}{|c|c|c|c|c|c|}
\hline & & \multicolumn{2}{|c|}{ Açılanma-sağ } & \multicolumn{2}{|c|}{ Açılanma-sol } \\
\hline & & $\mathbf{r}$ & $p$ & $\mathbf{r}$ & $p$ \\
\hline \multirow{2}{*}{ Total } & KHM-să & 0,117 & 0,248 & 0,134 & 0,183 \\
\hline & KHM-sol & 0,159 & 0,113 & 0,187 & 0,062 \\
\hline \multirow{2}{*}{ Erkek } & KHM-să & 0,054 & 0,711 & 0,069 & 0,634 \\
\hline & KHM-sol & 0,138 & 0,338 & 0,165 & 0,251 \\
\hline \multirow{2}{*}{ Kadın } & KHM-să̆ & 0,080 & 0,581 & 0,103 & 0,477 \\
\hline & KHM-sol & 0,103 & 0,476 & 0,150 & 0,299 \\
\hline
\end{tabular}

KHM: korakohumeral mesafe. Spearmankorelasyon testi.

\section{Sonuc}

Çalışmamız bazı limitasyonlar içermektedir. Bunlardan ilki olguları retrospektif olarak değerlendirmemizdi. Ayrıca, çalışmada sadece kemik yapılar dikkate alınmıştır. MR ile yapılacak dinamik ölçümler sıkışma bulguları ile morfolojik yatkınlık arasındaki ilişkiyi daha iyi ortaya koyabilirdi. Bununla birlikte, çalışmamız korakoid morfolojisiyle el dominans1 arasındaki ilişkiyi değerlendiren ilk çalışmadır. Ek olarak, korakoid aksı, önceki çalıșmaların aksine, açısal değerler üzerinden kantitatif olarak ölçülerek yaş, cinsiyet, taraf ve boy uzunluğu ile ilişkisi değerlendirilmiştir.

Çalışmamızın en önemli bulgusu kadınlarda KHM'nin daha dar olmasidır. Ayrıca, korakoid açılanması ile KHM mesafe arasında herhangi bir ilişki tespit edilmedi. 
Literatürde daha önce rastlamadığımız bir diğer bulgumuz ise el dominansının korakoid açılanması ve KHM üzerinde bir etkisinin olmamasiydi.

Subkorakoidal anatominin tam olarak ortaya konması bu bölgedeki sıkışmanın daha iyi anlaşılmasını sağlayacaktır. Çalışmamız, korakoid açılanması ve korakohumeral değerleri ortaya koymanın yanısıra, el dominansı ve korakoid açılanmanın korakohumeral mesafe üzerinde bir etkisi olmadığını göstermiştir. Elde edilen bulguların bireysel farklılıkları ortaya koyarak subkorakoidal sıkışmanın daha iyi anlaşılmasına katkı sağlayacağını düşünüyoruz.

\section{Araștırmanın Etik Boyutu}

Çalıșma için, ilgili üniversite Tıp Fakültesi Etik Kurulu'ndan etik kurul izni alınmıştır. (24.09.2019-2019.171.09.31). Araştırma Helsinki Bildirgesi ilkelerine uygun olarak yürütülmüş̧ür.

\section{Bilgilendirilmiş Onam}

Çalışma retrospektif olarak dataları kullandığından eklenmemiştir.

\section{Yazar Katkıları}

Araştırmanın hipotezi A.S. tarafından oluşturulmuştur. Sonuca ulaşabilmek için gerekli dizayn M.Ü.Ç ve İ.A. tarafından oluşturulmuştur. Araştırmamız için gerekli verilerin toplanması İ.Y., A.Ș. ve H.S. tarafından toplanmıştır. Bulguların mantıklı açıklanmasını ve sunumunu A.S. ve Y.M.D gerçekleştirmiştir. Kaynak taramasını H.S. ve M.Ü.Ç yapmıştır. Çalışmamızın yazımı A.S. ve H.S., eleştirel incelemesi ise İ.A. tarafından yapılmıştır.

\section{Çıkar Çatışması Beyanı}

Yazarların herhangi bir çıkara dayalı ilişkisi yoktur.

\section{Araştırma Desteği}

Çalışmayı maddi olarak destekleyen kişi/kuruluş yoktur.

\section{Beyanlar}

$\mathrm{Bu}$ çalışma daha önce hiçbir yerde sunulmamıştır.

\section{Kaynaklar}

1. De Witte $P$, Nagels J, van Arkel ER, Visser CP, Nelissen RG, de Groot JH. Study protocol subacromial impingement syndrome: the identification of pathophysiologic mechanisms (SISTIM). BMC Musculoskelet Disord. 2011;12:282.

2. Seitz AL, McClure PW, Finucane S, Boardman ND 3rd, Michener LA. Mechanisms of rotator cuff tendinopathy: intrinsic, extrinsic, or both? ClinBiomech (Bristol Avon). 2011;26(1):1-12.

3. Cezayir E, Ateş Y, Ersoy M, Tekdemir I. Akromion ve korakoakromiyal kavsin morfometrik anatomisi. Acta Orthop Traumatol Turc.1995;29(3):224-226.

4. Le Reun O, Lebhar J, Mateos F, Voisin JL, Thomazeau H, Ropars M. Anatomical and morphological study of the subcoracoacromial canal. Orthop Traumatol Surg Res. 2016;102(8S):S295-S299.

5. Cunningham G, Lädermann A Redefining anterior shoulder impingement: a literature review. Int Orthop. 2018;42(2):359-366.

6. Lo IK, Parten PM, Burkhart SS. Combined subcoracoid and subacromial impingement in association with anterosuperior rotator cuff tears: An arthroscopic approach. Arthroscopy. 2003;19(10):1068-78.

7. Lo IK, Burkhart SS. The etiology and assessment of subscapularis tendon tears: a case for subcoracoid impingement, the roller-wringer effect, and TUFF lesions of the subscapularis. Arthroscopy. 2003;19(10):1142-50.

8. Balke M, Banerjee M, Greshake O, Hoeher J, Bouillon B, Liem D. The coracohumeral distance in shoulders with traumatic and degenerative subscapularis tendon tears. Am J Sports Med. 2016;44(1):198-201.

9. Giaroli EL, Major NM, Lemley DE, Lee J. Coracohumeral interval imaging in subcoracoid impingement syndrome on MRI. AJR Am J Roentgenol. 2006;186(1):242-6.

10. Dugarte AJ, Davis RJ, Lynch TS, Schickendantz MS, Farrow LD. Anatomic Study of Subcoracoid Morphology in 418 Shoulders: Potential Implications for Subcoracoid Impingement.Orthop $J$ Sports Med. 2017;5(10):2325967117731996.

11. Gumina S, Postacchini F, Orsina L, Cinotti G. The morphometry of the coracoid process - it's aetiologic role in subcoracoid impingement syndrome. Int

12. Arrigoni P, Brady PC, Burkhart SS. Calcific tendonitis of the subscapularis tendon causing subcoracoid stenosis and coracoid impingement. Arthroscopy. 2006;22(10):1139.e1-3.

13. Cetinkaya M, Ataoglu MB, Ozer M, Ayanoglu T, Kanatli U. Subscapularis tendon slip number and coracoid overlap are more related parameters for subcoracoid impingement in subscapularis tears: a magnetic resonance imaging comparison study. Arthroscopy. 2017;33(4):734-42.

14. Hekimoğlu B, Aydın H, Kızılgöz V, Tatar IG, Ersan O. Quantitative measurement of humeroacromial, humericoracoid and coracoclavicular intervals for the diagnosis of subacromial and subcoracoid impingement of shoulder joint. Clin Imaging. 2013;37(2):201-10

15. Gerber C, Terrier F, Zehdner R, Ganz R. The subcoracoid space.An anatomic study. Clin Orthop Relat Res 1987;(215):132-8.

16. Leite MJ, Sá MC, Lopes MJ, Matos RM, Sousa AN, Torres JM. Coracohumeral distance and coracoid overlap as predictors of subscapularis and long head of the biceps injuries. J Shoulder Elbow Surg. 2019;28(9):1723-1727.

17. Verma U, Singroha R, Malik P, Rathee SK.A study on morphometry of coracoid process of scapula in north Indian population. Int J Res Med Sci. 2017;5(11):4970-4974.

18. Brunkhorst JP, Giphart JE, LaPrade RF, Millett PJ. Coracohumeral distances and correlation to arm rotation: An in vivo3-dimensional biplane fluoroscopy study. Orthop J Sports Med. 2013;1(2):2325967113496059.

19. Kleist KD, Freehill MQ, Hamilton L, Buss DD, Fritts H. Computed tomography analysis of the coracoid process and anatomic structures of the shoulder after arthroscopic coracoid decompression: a cadaveric study. J Shoulder Elbow Surg. 2007;16(2):245-50.

20. Suenaga N, Minami A, Kaneda K. Postoperative subcoracoid impingement syndrome in patients with rotator cuff tear. $J$ Shoulder Elbow Surg. 2000;9(4):275-8. 
21. Park JY, Lhee SH, Oh KS, Kim NR, Hwang JT. Is arthroscopic coracoplasty necessary in subcoracoid impingement syndrome? Arthroscopy. 2012;28(12):1766-75.

22. Freehill MQ. Coracoid impingement: diagnosis and treatment. $J$ Am Acad Orthop Surg. 2011;19(4):191-7.

23. Asal N, Sahan MH. Radiological Variabilities in Subcoracoid Impingement: Coracoid Morphology, Coracohumeral Distance, Coracoglenoid Angle, and CoracohumeralAngle. Med Sci Monit.2018;24:8678-8684.

24. Richards DP, Burkhart SS, Campbell SE. Relation between narrowed coracohumeral distance and subscapularis tears. Arthroscopy. 2005;21(10):1223-8.

25. MacMahon PJ, Taylor DH, Duke D, Brennan DD, O’Brien J, Eustace $\quad$ SJ. Contribution of fullthickness supraspinatus tendon tears to acquired subcoracoid impingement. Clin Radiol. 2007;62(6):556-63. 